\title{
A Thiadiazole-Based Covalent Organic Framework: A Metal-Free Electrocatalyst toward Oxygen Evolution Reaction
}

\author{
${ }_{3}$ Sujan Mondal, ${ }^{\nabla}$ Bishnupad Mohanty, ${ }^{\nabla}$ Maryam Nurhuda, Sasanka Dalapati, Rajkumar Jana, \\ ${ }_{4}$ Matthew Addicoat, Ayan Dutta, Bikash Kumar Jena,* and Asim Bhaumik*
}

Cite This: https://dx.doi.org/10.1021/acscatal.9b05470

Read Online

\section{ACCESS |}

山ll Metrics \& More

Article Recommendations

Supporting Information

5 ABSTRACT: Covalent organic frameworks (COFs) have attracted surging interest lately due to 6 their wide potential in several frontline application areas like gas storage, sensing, photovoltaics, 7 fuel cells, active catalyst supports, and so on. However, only very few reports are available for the 8 metal-free electrocatalysis over COFs. Herein, we developed a new thiadiazole-based COF, C4$9 \mathrm{SHz}$ COF, through the reaction between 1,3,5-tris(4-formylphenyl)benzene and 2,5-dihydrazinyl10 1,3,4-thiadiazole that possesses a very high specific surface area of $1224 \mathrm{~m}^{2} \mathrm{~g}^{-1}$, unique molecular 11 architecture, high porosity, and abundant active sites. The as-synthesized $\mathrm{C} 4-\mathrm{SHz} \mathrm{COF}$ displayed 12 superior electrocatalytic oxygen evolution reaction (OER) activity and excellent long-term 13 durability. The electrocatalytic performance of the C4-SHz COF achieved a current density of $10 \mathrm{~mA} / \mathrm{cm}^{2}$ at an overpotential of 320 $14 \mathrm{mV}$. The higher activity of the C4-SHz COF could be attributed to the high Brunauer-Emmett-Teller surface area, porosity, and 15 network structure of the $\pi$-conjugated organic building blocks, which allowed fast charge and mass transport processes. This work 16 validates the promising potential of a metal-free COF electrocatalyst toward the OER and its capability to replace carbon-based 17 electrocatalysts.

18 KEYWORDS: covalent organic frameworks (COFs), thiadiazole moiety, metal-free electrocatalyst, oxygen evolution reaction (OER), 19 water splitting

\section{$20 \square$ INTRODUCTION}

21 Rapid decay of fossil fuels combined with environmental crises 22 associated with carbon emissions significantly affected the 23 economy and ecology of the whole world. Thus, the demand 24 for renewable energy is surging over the years, and electro25 chemical water splitting can be considered as a green and 26 promising technology to overcome this problem. The 27 electrochemical water splitting plays a crucial role in advanced 28 energy technologies, such as solar fuel production, super29 capacitor, metal-air batteries, etc. ${ }^{2-5}$ Still, water oxidation 30 (oxygen evolution reaction, OER) requires a higher energy 31 input due to the involvement of the multi-electron transfer 32 reaction pathway and its low efficiency. Hence, the 33 commercialization of water splitting technology requires stable, 34 highly active, and low-cost water oxidation electrocatalysts. 35 Currently, precious transition metal oxide-based electro36 catalysts such as $\mathrm{RuO}_{2}$ and $\mathrm{IrO}_{2}$ are highly active toward the 37 OER from alkaline water. However, high cost, scarcity, and low 38 stability hamper the utilization of clean and sustainable energy 39 technologies $^{6,7}$ in this context. Thus, for the past couple of 40 years, extensive efforts have been devoted for the development 41 of earth-abundant, low-cost, and efficient transition metal42 based electrocatalysts such as oxides, chalcogenides, phos43 phides, nitride, metal-free catalysts, etc., for the OER. ${ }^{8-14}$ 44 However, most of the transition metal-based catalysts still 45 suffer from lower catalytic activity, inferior conductivity, and 46 poor operational durability.
Simultaneously, over the past few years, intensive research 47 has been carried out for developing efficient metal-free 48 catalysts. $^{2,3}$ Metal-free electrocatalysts have several unique 49 advantages, such as their environment-friendly nature, earth- 50 abundant, cost-effective, and resistance to a wide $\mathrm{pH}$ range. 51 For electrochemical OER applications, several metal-free 52 catalysts have been developed in recent times. ${ }^{15-17}$ Among 53 different metal-free porous nanomaterials, covalent organic 54 frameworks (COFs) ${ }^{18,19}$ are the emerging class of porous 55 organic polymers with precisely controllable structural motifs 56 linked through covalent bonds. COFs possess extraordinary 57 properties like large surface area, high crystallinity, tunable 58 pore size, and unique molecular architecture. ${ }^{20-24}$ Due to these 59 unique properties, COFs have been used in a wide range of 60 applications. ${ }^{25-27}$ High surface area, tunable structures with 61 appropriate building blocks, and porous nature of the COFs 62 made them ideal for electrocatalysis. ${ }^{28}$ Accordingly, substantial 63 progress has been made for the design and synthesis of COFs 64 from low-cost monomer precursors. Till now, COFs have been 65 explored as a support material of graphene, conductive carbon, 66

Received: December 18, 2019

Revised: March 23, 2020 
a)

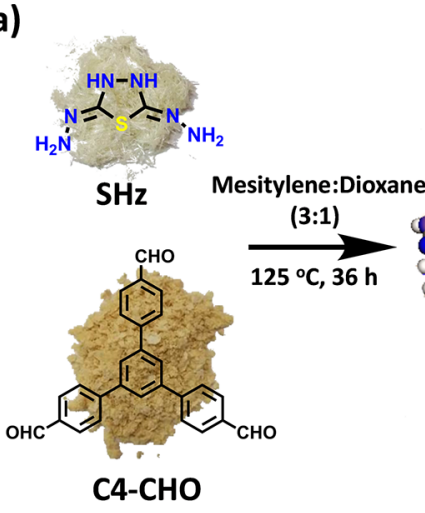

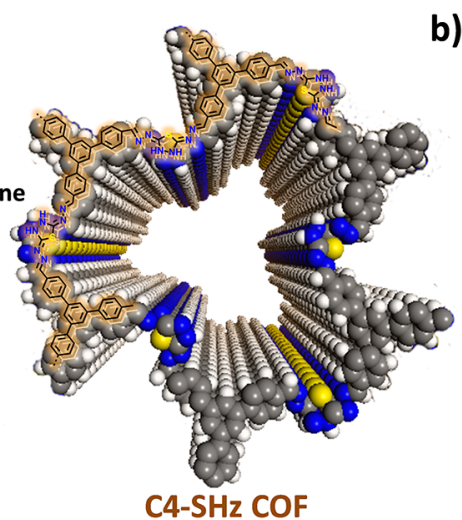

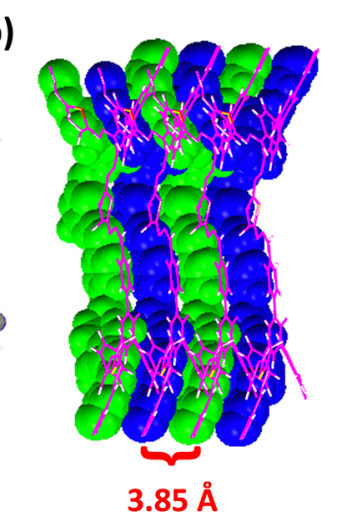

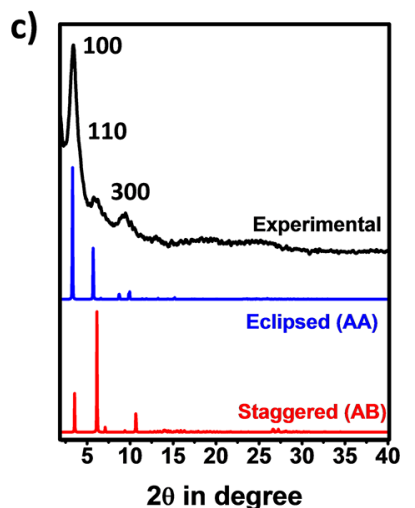

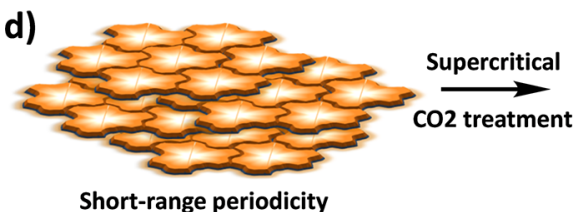

Short-range periodicity

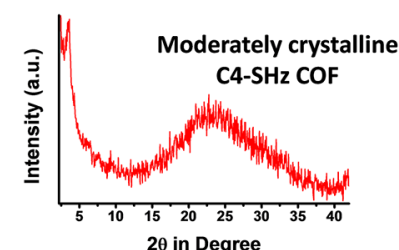

$2 \theta$ in Degree

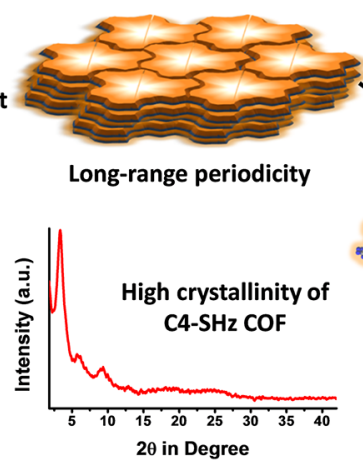

$2 \theta$ in Degree

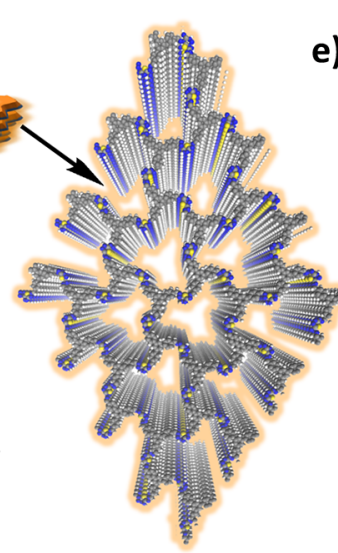

e)

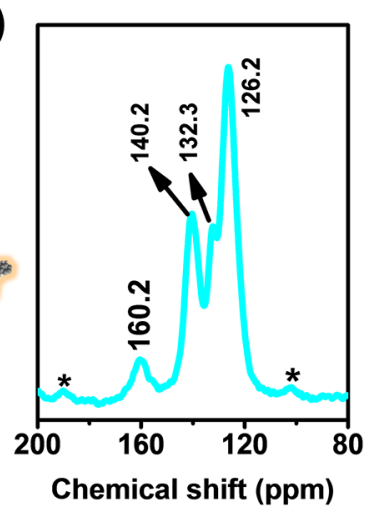

Figure 1. Schematic presentation of the COF (a) proposed structure and (b) packing diagram. (c) Comparison of experimental PXRD pattern of the crystalline $\mathrm{C} 4-\mathrm{SHz}$ COF with simulated PXRD patterns of the $\mathrm{C} 4-\mathrm{SHz} \mathrm{COF}$. (d) Graphical representation of switching shortly to long-range periodicity. (e) Solid-state ${ }^{13} \mathrm{C}$ MAS NMR spectrum of the COF; the spinning sidebands are represented by asterisks.

${ }_{67}$ carbon nanotubes (CNTs), etc., for electrocatalytic applica${ }_{68}$ tions. For example, Kamiya et al. have reported covalent ${ }_{69}$ triazine frameworks as support materials for Pt nanoparticle 70 and studied its ORR activity. ${ }^{29}$ Mullangi et al. used flexible ${ }_{71}$ COFs as support materials for electrocatalytic OER 72 applications. ${ }^{28}$ Similarly, Aiyappa et al. designed Co-COF ${ }_{73}$ and studied its OER activity, ${ }^{30}$ whereas $\mathrm{Fe}$ and Co NPs 74 supported over COFs have been employed in electrochemical 75 oxygen reduction reaction (ORR). ${ }^{31}$ Although there are very ${ }_{76}$ few reports on the usage of COFs as photocathodes for light${ }_{77}$ induced hydrogen evolution reaction (HER) via water ${ }_{78}$ splitting, ${ }^{32}$ the use of a crystalline COF as a metal-free OER 79 electrocatalyst has been rarely explored till date. ${ }^{33}$

80 In this article, we have introduced an unprecedented imine${ }_{81}$ linked thiadiazole-based crystalline $\mathrm{COF}(\mathrm{C} 4-\mathrm{SHz} \mathrm{COF})$ and ${ }_{82}$ explored its catalytic activity in the electrochemical water ${ }_{83}$ oxidation reaction. Through the general solvothermal protocol ${ }_{84}$ (Schiff base condensation using acetic acid), ${ }^{26,27,30}$ a nitrogen${ }_{85}$ rich thiadiazole moiety has been incorporated in the polymeric ${ }_{86}$ backbone of the $\mathrm{C} 4-\mathrm{SHz} \mathrm{COF}$, which exhibited superior 87 activity toward OER. The relevant characterization data ${ }_{88}$ suggested that the $\mathrm{C} 4-\mathrm{SHz}$ COF possesses a high specific ${ }_{89}$ surface area and crystalline metal-free organic framework 90 structure. The newly developed COF displayed an excellent ${ }_{91}$ electrocatalytic activity and durability under alkaline $\mathrm{pH}$ ${ }_{92}$ conditions, which is comparable to the other metal-free 93 electrocatalysts reported so far.

\section{RESULTS AND DISCUSSION}

The thiadiazole-based imine-linked $\mathrm{COF}$ (C4-SHz COF) was 95 synthesized through the general Schiff base condensation 96 polymerization between 1,3,5-tris (4-formylphenyl)benzene 97 (C4-CHO) and 2,5-dihydrazinyl-1,3,4-thiadiazole ( $\mathrm{SHz}) 98$ under the solvothermal condition for $36 \mathrm{~h}$ (Figure $1 \mathrm{a}$ and $99 \mathrm{fl}$ Figures S1-S3, Supporting Information). The resultant as- 100 synthesized imine-linked framework has shown a low sign of 101 crystallinity (Figure 1d), and this could often occur due to the 102 self-assembly through weak $\pi-\pi$ stacking interaction of 103 individual COF layers. To get the well-defined molecular 104 stacked framework, the as-synthesized $\mathrm{C} 4-\mathrm{SHz}$ COF material 105 was activated using supercritical carbon dioxide treatment 106 following the reported protocol by Medina et al. ${ }^{34}$ The more 107 prominent desired peaks in X-ray diffraction for the post- 108 activated material is observed (Figure 1d), suggesting the well- 109 defined structure of pores. Surprisingly, the measured $S_{\mathrm{BET}} 110$ values are also mirroring this trend by narrowing the pore size 111 (Figure S4, Supporting Information).

The crystalline structure of the $\mathrm{C} 4-\mathrm{SHz} \mathrm{COF}$ is resolved 113 through the experimental powder X-ray diffraction measure- 114 ment in combination with theoretical simulations and Pawley 115 refinement (Figure S5 and Tables S1 and S2, Supporting 116 Information). As seen in Figure 1c, a distinct peak at $2 \theta=3.3^{\circ} 117$ is assigned to the 100 crystal plane of the COF. Additionally, 118 relatively weak peaks at $2 \theta=5.8$ and $9.9^{\circ}$ correspond to the 119 reflection from 110, and 300 planes are also observed. The 120 weak broad peak centered at $2 \theta=20-26^{\circ}$ (002 plane) is 121 possibly due to the interlayer $\pi-\pi$ stacking of the COF, and 122 distances between the individual 002 planes are ca. $3.85 \AA 123$ 
124 (Figure 1b). A probable 2D model structure was constructed 125 using Materials Studio 7 in the $P 1$ space group. An asymmetric 126 unit in the crystal structure and graphical representation of the 127 2D layered COF is shown in Figure S6 (Supporting 128 Information). The simulated PXRD pattern of the eclipsed 129 AA stacking model is well fitted with the experimental 130 diffraction data (Figure 1c). In contrast, the PXRD pattern 131 obtained from the $\mathrm{AB}$ stacking model deviates from the 132 experimentally observed data, especially in terms of peak 133 intensity ratios. The perfect agreement in favor of the 134 experimental X-ray pattern was further confirmed by Pawley 135 refinement $\left[R_{\mathrm{wp}}=7.23 \%, \mathrm{Rp}=5.32 \%\right]$ (Figure $\mathrm{S} 5$ ). The unit 136 cell parameters were as follows: $a=31.00 \AA$, $b=31.46 \AA, c=$ $1377.70 \AA$; $\alpha=99.26^{\circ}, \beta=87.67^{\circ}$, and $\gamma=120.51^{\circ}$.

138 The specific surface area and porous nature of the $\mathrm{C} 4-\mathrm{SHz}$ $139 \mathrm{COF}$ were examined by conducting $\mathrm{N}_{2}$ adsorption-desorption 140 analysis at $77 \mathrm{~K}$. As shown in Figure 2a, the $\mathrm{C} 4-\mathrm{SHz} \mathrm{COF}$
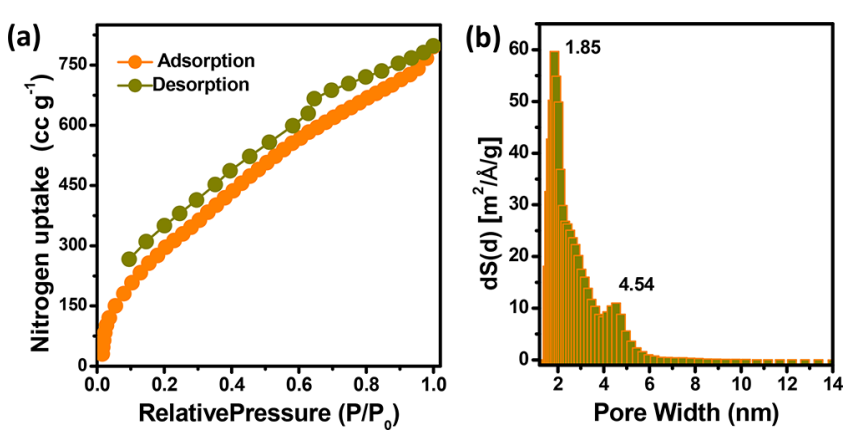

Figure 2. (a) $\mathrm{N}_{2}$ adsorption-desorption analysis of the $\mathrm{C} 4-\mathrm{SHz} \mathrm{COF}$ and (b) NLDFT pore size distribution plots.

141 exhibits a combination of type I and IV isotherms. A significant 142 nitrogen uptake at low relative pressures $\left(P / P_{0}<0.03\right)$ 143 followed by a gradual increase in adsorption at a higher $P / P_{0}$ 144 value suggested the distinctive features for the coexistence of 145 micropores and mesopores along with interparticle pores. ${ }^{35-38}$ 146 The corresponding pore size distribution plot (Figure $2 b$ ), as 147 determined from the adsorption branch of the isotherm based 148 on nonlocal density functional theory (NLDFT), revealed the 149 presence of micropores and mesopores in our $\mathrm{C} 4-\mathrm{SHz} \mathrm{COF}$ 150 material. The calculated BET (Brunauer-Emmett-Teller, $\left.151 S_{\mathrm{BET}}\right)$ surface area from this isotherm was $1224 \mathrm{~m}^{2} \mathrm{~g}^{-1}$, and 152 the total pore volume was $1.12 \mathrm{cc} \mathrm{g}^{-1}$. The simulated BET 153 surface area of the AA stacked model of the $\mathrm{C} 4-\mathrm{SHz} \mathrm{COF}$ has 154 been computed using the DFTB calculations. The correspond155 ing simulated specific surface area was found to be $2339 \mathrm{~m}^{2} \mathrm{~g}^{-1}$ 156 (Figure S7, Supporting Information). The noticeable dis157 tinction in BET surface area from the experimental data is 158 related to the crystallinity of the COF material, and such 159 deviations were also reported for other imine-based 160 COFs. ${ }^{39-42}$

161 The structural growth and imine linkage formation of the $162 \mathrm{COF}$ are confirmed by FTIR and ${ }^{13} \mathrm{C}$ MAS NMR analyses. In 163 the FTIR spectrum of the $\mathrm{C} 4-\mathrm{SHz}$ COF (Figure 3a), the 164 absorption band at $1693 \mathrm{~cm}^{-1}$ corresponded to $\mathrm{C}=\mathrm{N}$ 165 absorption, which is also confirmed by the resonance signal 166 at $160.2 \mathrm{ppm}$ in ${ }^{13} \mathrm{C} \mathrm{NMR}$. The peak at $3416 \mathrm{~cm}^{-1}$ could be 167 attributed to $\mathrm{N}-\mathrm{H}$ stretching vibration. The complete 168 utilization of the aldehyde sources was confirmed by the 169 missing peak at $1698 \mathrm{~cm}^{-1}$ in the IR spectrum and the absence 170 of aldehydic resonance peak at $190 \mathrm{ppm}$ in ${ }^{13} \mathrm{C}$ NMR. In the
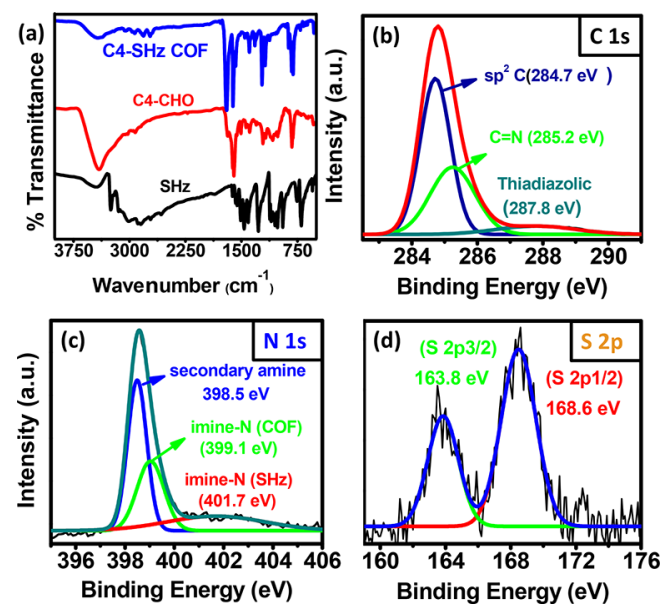

Figure 3. (a) IR spectrum of the $\mathrm{C} 4-\mathrm{SHz} \mathrm{COF}$ along with the spectra of $\mathrm{SHz}$ and $\mathrm{C} 4-\mathrm{CHO}$. (b) C 1s X-ray photoelectron spectroscopy (XPS). Deconvoluted high-resolution (c) N 1s XPS spectra and (d) S $2 \mathrm{p}$ XPS spectra of the thiadiazole-based COF.

spectrum in Figure 1e, the resonance signal at $160.2 \mathrm{ppm}$ is 171 ascribed to the carbon atom adjacent to the $\mathrm{S}$ atom of the $\mathrm{SHz} 172$ moiety. The peak at $140.2 \mathrm{ppm}$ is indicative of substituted 173 quaternary carbons of the polymeric network. The resonance 174 peak at $132.3 \mathrm{ppm}$ is attributed to the carbon atom of the 175 aldehyde moiety that connected to the imine carbon of the 176 organic framework. The additional peak at $126.2 \mathrm{ppm} 177$ appeared due to the $\mathrm{sp}^{2}$-hybridized aromatic carbons. 178

To gain further information about the surface chemistry and 179 chemical composition, we have carried out the XPS analysis of 180 the $\mathrm{C} 4-\mathrm{SHz}$ COF. As shown in Figure 3c, the N 1s spectrum 181 can be deconvoluted into three component peaks ascribed to 182 secondary amine $(-\mathrm{NH})$ of the $\mathrm{SHz}$ moiety $(398.5 \mathrm{eV}), 183$ imine $-\mathrm{N}(399.1 \mathrm{eV})$ of the newly formed COF networks, and 184 imine-N $(401.7 \mathrm{eV})$ of the $\mathrm{SHz}$ moiety. ${ }^{41}$ The $\mathrm{C}$ nuclei with 185 different environments were investigated by a deconvoluted 186 high-resolution C 1s XPS scan (Figure 3b). The major 187 component at $284.7 \mathrm{eV}$ is attributed to the aromatic $\mathrm{sp}^{2} \mathrm{C} 188$ atom. Another component at $285.2 \mathrm{eV}$ can be assigned to the 189 $\mathrm{N}$ atom associated with imine linkage. The peak at a higher 190 binding energy $(287.8 \mathrm{eV})$ is probably due to thiadiazolic C of 191 the COF. Strong characteristic S 2p doublet peaks (Figure 3d) 192 were observed at 163.8 (S 2p3/2) and $168.6 \mathrm{eV}\left(\mathrm{S} \mathrm{2p1/2)}{ }^{43} 193\right.$

The thermal stability of the covalent framework was 194 estimated by using thermogravimetric analysis (TGA) under 195 the aerobic environment. As seen from Figure S8 (Supporting 196 Information), an initial weight loss could be assigned to the 197 trapped guest molecule in the porous framework. Then, with 198 the continuous increase in temperature, the organic framework 199 is stable up to $350{ }^{\circ} \mathrm{C}$. With a further increase in temperature, a 200 continuous weight loss is associated with the burning of 201 organics present in the material. The representative FESEM 202 (Figure 4a) and HRTEM (Figure 4b) images of the as- $203 \mathrm{f} 4$ synthesized thiadiazole COF have clearly shown regularly their 204 spherical morphology with diameters of $0.5-0.8 \mu \mathrm{m}$. After the 205 supercritical $\mathrm{CO}_{2}$ activation, it was observed that the smooth 206 spherical surface of the as-synthesized COF material trans- 207 formed to the microflower-shaped structure (Figure 4c-f) 208 with the size distribution of $1.2-1.8 \mu \mathrm{m}$. This is also reflected 209 by the nitrogen sorption isotherm with enhancing the BET 210 surface area (Figure S4). 


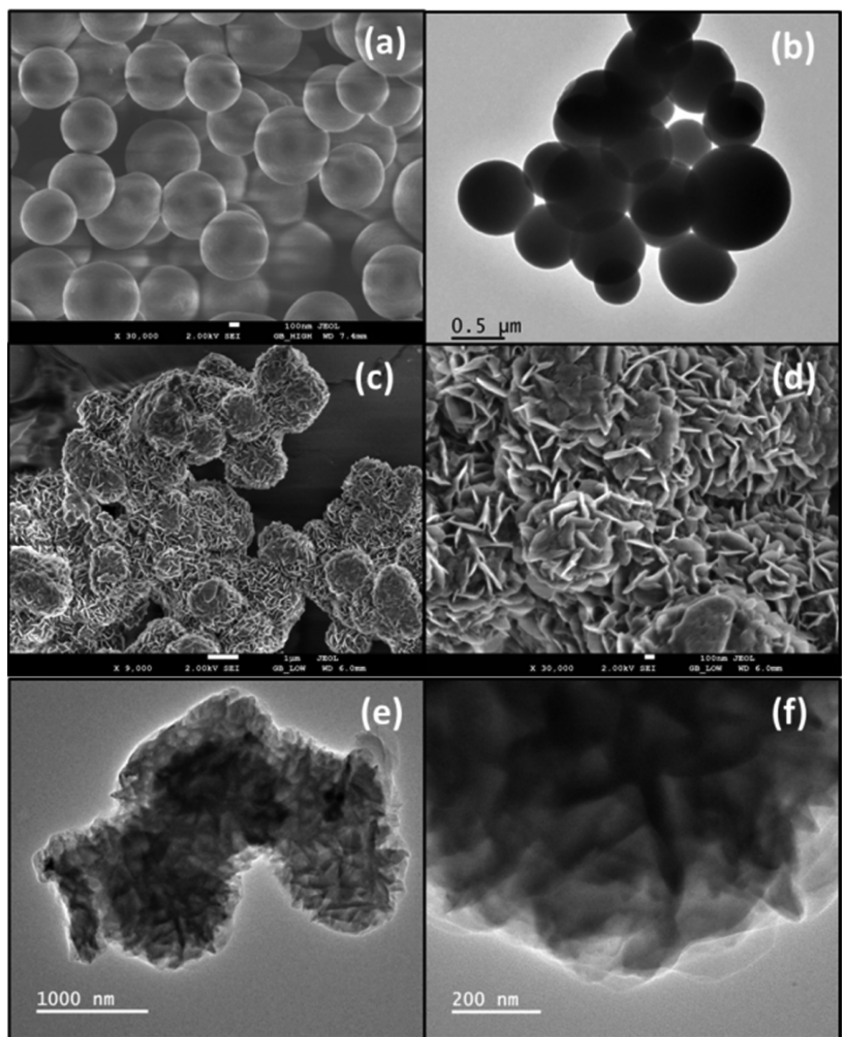

Figure 4. FESEM micrographs of the (a) as-synthesized and (c, d) crystalline $\mathrm{C} 4-\mathrm{SHz} \mathrm{COF}$. Representative TEM images of the (b) assynthesized and (e, f) crystalline $\mathrm{C} 4-\mathrm{SHz} \mathrm{COF}$ material.

212 To determine the electrocatalytic OER activity of the as213 synthesized catalyst, linear sweep voltammetry (LSV) was 214 recorded. The OER activity of the $\mathrm{C} 4-\mathrm{SHz} \mathrm{COF}$ was 215 compared with the state-of-the-art catalyst $\mathrm{IrO}_{2} / \mathrm{C}$ and bare 216 GCE under similar conditions. Before the LSV measurement, the $\mathrm{C} 4-\mathrm{SHz} \mathrm{COF}$ catalyst was electrochemically precondi- 217 tioned to reach a stable state (Figure S9, Supporting 218 Information). All the LSV plots are presented after $i R 219$ compensation. The $i R$ compensation process is explained in 220 the Supporting Information (Figure S10). Figure 5a presents $221 \mathrm{fs}$ the $i R$-compensated LSV polarization plots. As expected, the 222 bare glassy carbon electrode (GCE) exhibits a very low anodic 223 current density with higher overpotential values, suggesting its 224 negligible OER activity. The C4-SHz COF-modified GCE 225 shows a sharp increase in the anodic current density, which 226 indicates its intrinsic OER activity. For electrocatalytic activity, 227 the overpotential $(\eta)$ gives an idea about the extent of 228 polarization upon passage of the faradic current and reflects the 229 efficiency of the catalysts. The catalyst C4-SHz COF possesses 230 the higher activity with a lower onset overpotential of $250 \mathrm{mV}, 231$ which is higher than that of benchmark catalyst $\mathrm{IrO}_{2} / \mathrm{C}$. The 232 current density of $10 \mathrm{~mA} / \mathrm{cm}^{2}$ is the critical value for driving 233 solar fuel conversion and used as a benchmark for comparing 234 electrocatalytic performance. The as-synthesized C4-SHz COF 235 achieved a current density of $10 \mathrm{~mA} / \mathrm{cm}^{2}$ at a lower 236 overpotential of $320 \mathrm{mV}$, which is lower than benchmark 237 catalyst $\mathrm{IrO}_{2} / \mathrm{C}$. The overpotential of the $\mathrm{C} 4-\mathrm{SHz} \mathrm{COF}$ is 238 comparable with most of the reported metal-free OER 239 electrocatalysis (Table S3, Supporting Information). This 240 result suggests the promising electrocatalytic activity of the 241 highly crystalline $\mathrm{C} 4-\mathrm{SHz}$ COF toward the OER. The OER 242 activity is also compared with a moderately crystalline $\mathrm{C} 4-\mathrm{SHz} 243$ COF. The highly crystalline $\mathrm{C} 4-\mathrm{SHz}$ COF exhibits a lower 244 overpotential with enhanced current density in comparison to 245 moderately crystalline C4-SHz COF (Figure S11, Supporting 246 Information). Further, the OER activity of the highly 247 crystalline $\mathrm{C} 4-\mathrm{SHz} \mathrm{COF}$ is checked in different conditions, 248 i.e., acidic ( $\left.0.5 \mathrm{M} \mathrm{H}_{2} \mathrm{SO}_{4}\right)$ and neutral (1 M PBS) solutions. 249 The C4-SHz COF exhibits the higher OER activity in $1 \mathrm{M}_{250}$ $\mathrm{KOH}$ (Figure S12, Supporting Information).

251

The reaction dynamics and mechanism of the as-synthesized 252 catalysts toward the OER were investigated by measuring the 253
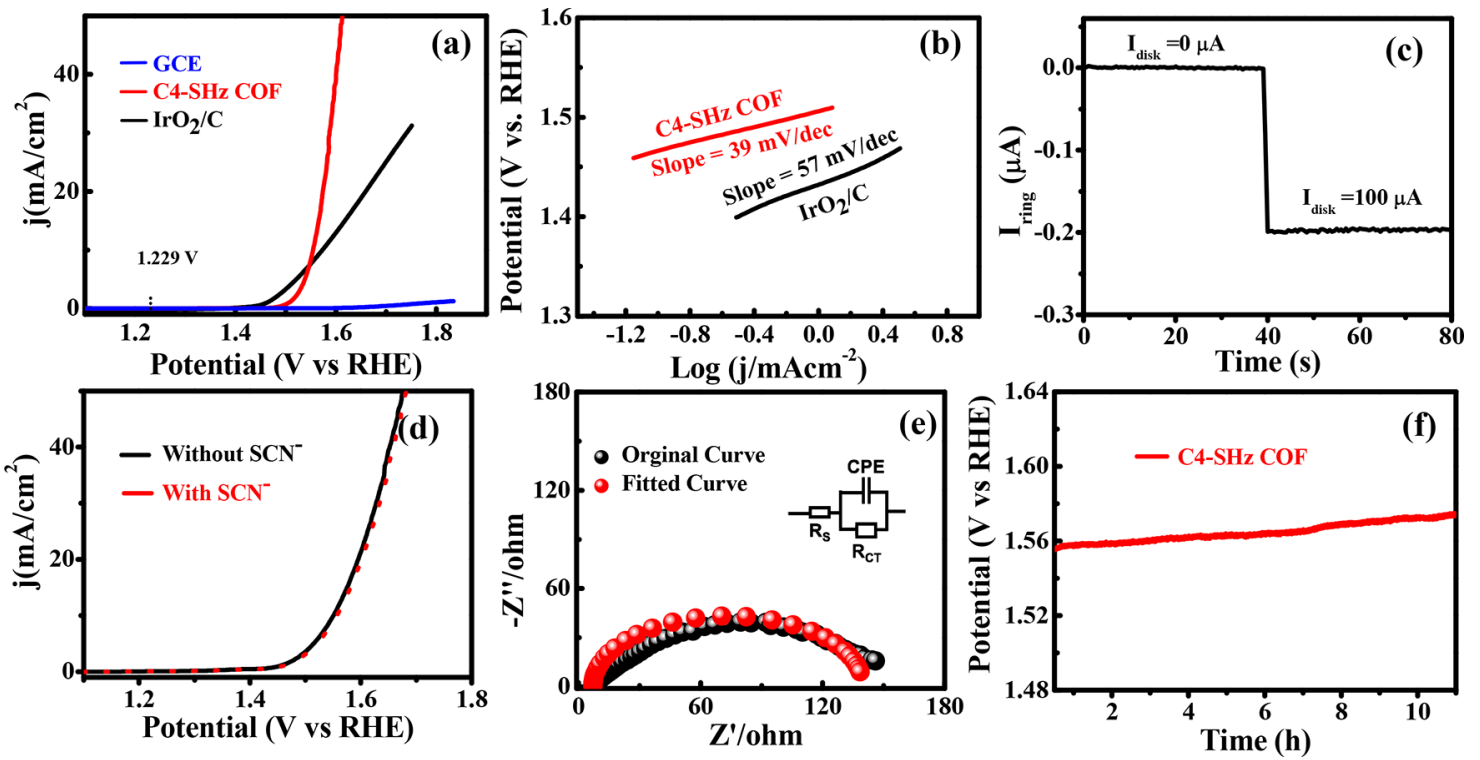

Figure 5. OER performance of the catalysts in $1 \mathrm{M} \mathrm{KOH}$ with a scan rate of $5 \mathrm{mV} / \mathrm{s}$. (a) LSV polarization plots of the $\mathrm{C} 4-\mathrm{SHz} \mathrm{COF}$, IrO $2 / \mathrm{C}$, and GCE. (b) Tafel plots of the C4-SHz COF and $\mathrm{IrO}_{2} / \mathrm{C}$. (c) Faradic efficiency calculation of the C4-SHz COF by using the RRDE technique. (d) LSV polarization plot of the C4-SHz COF before and after the addition of $10 \mathrm{mM} \mathrm{KSCN}$. (e) EIS Nyquist plot for the C4-SHz COF. (f) Chronopotentiometry measurement shows the stability of $\mathrm{C} 4-\mathrm{SHz} \mathrm{COF}$. 
254 Tafel slope from Tafel plots. The Tafel plots are obtained from 255 the LSV measurements and reflect the relationship between 256 the overpotential $(\eta)$ and the log of current density. The Tafel 257 slope is derived from the linear part of the Tafel plot, and lower 258 the Tafel slope value indicates the higher electrocatalytic 259 activity. The C4-SHz COF exhibits the lower Tafel slope of 39 $260 \mathrm{mV} / \mathrm{dec}$, which is lower than that for $\mathrm{IrO}_{2} / \mathrm{C}(57 \mathrm{mV} / \mathrm{dec})$ 261 (Figure 5b). The Tafel slope of the $\mathrm{C} 4-\mathrm{SHz} \mathrm{COF}$ is lower than 262 that of other reported metal-free catalysts. The exchange 263 current density $\left(j_{0}\right)$ of the $\mathrm{C} 4-\mathrm{SHz} \mathrm{COF}$ is calculated from the 264 Tafel plot by the extrapolation method (Figure S13, 265 Supporting Information). The exchange current density $\left(j_{0}\right)$ 266 of the C4-SHz COF is estimated to be $3.95 \times 10^{-4} \mathrm{~mA} / \mathrm{cm}^{2}$. 267 The value of $j_{0}$ is also proportional to the electrochemically 268 active surface area. The small Tafel slope and large exchange 269 current density indicate that the $\mathrm{C} 4-\mathrm{SHz} \mathrm{COF}$ can produce 270 superior metal-free OER performance. The faradic efficiency 271 (FE) of the catalysts is measured by the rotating ring-disk 272 electrode (RRDE) experiment. ${ }^{44,45}$ The RRDE experimental 273 details are discussed in the Supporting Information. The FE is 274 calculated from the ratio of the ring current to the disk current 275 (eq S3, Supporting Information). A constant current of $100 \mu \mathrm{A}$ 276 is applied to the disk electrode, and a $19.6 \mu \mathrm{A}$ current was 277 generated at the ring electrode (Figure 5c), which corresponds 278 to the promising $\mathrm{FE}$ of the $\mathrm{C} 4-\mathrm{SHz} \mathrm{COF}$ (98\%). The 279 formation of the oxygen bubble during the OER was supported 280 by the polarization curve of the oxygen reduction reaction 281 (ORR) collected from the ring electrode at a constant disk 282 potential of $1.50 \mathrm{~V}$ (Figure S14a, Supporting Information). 283 The number of electron transfer during the OER was also 284 calculated from the RRDE measurement. During OER 285 polarization, a very negligible current density was observed 286 in the ring electrode that is assigned to the electro-oxidation of 287 generated $\mathrm{H}_{2} \mathrm{O}_{2}$ (Figure $\mathrm{S} 14 \mathrm{~b}$ ). This observation validates the 288 four-electron pathway for the OER.

289 Generally, the precursor used for the synthesis of the COF 290 or the electrolyte used for testing the electrocatalytic activity 291 contains some metal catalysts (i.e., $\mathrm{Fe}^{3+}$ ), and it may contribute 292 toward the OER activity of the as-synthesized materials. To 293 rule out the contribution of metal ions (i.e., $\mathrm{Fe}^{3+}$ ), $\mathrm{SCN}^{-}$tests 294 were carried out. The LSV data of the $\mathrm{C} 4-\mathrm{SHz} \mathrm{COF}$ is 295 collected before and after the addition of the $\mathrm{SCN}^{-}$ions, and it 296 suggests that $\mathrm{SCN}^{-}$ions did not affect the OER activity, i.e., 297 the OER activity is due to the metal-free C4-SHz COF catalyst 298 (Figure 5d). This suggests that both the $\mathrm{C} 4-\mathrm{SHz} \mathrm{COF}$ and 299 electrolyte $(\mathrm{KOH})$ are free from metal impurities. ${ }^{14}$ The 300 enhanced catalytic activity of the $\mathrm{C} 4-\mathrm{SHz} \mathrm{COF}$ was further 301 accessed by calculating active sites and the intrinsic catalytic 302 activity. Therefore, we explored the mass activity, specific 303 activity, electrochemically active surface area (ECSA), and 304 roughness factor $\left(R_{\mathrm{f}}\right)$ of $\mathrm{C} 4-\mathrm{SHz} \mathrm{COF}$ catalysts. At $\eta=320$ $305 \mathrm{mV}$, the mass activity and specific activity for the $\mathrm{C} 4-\mathrm{SHz} \mathrm{COF}$ 306 catalyst were found to be $286 \mathrm{~A} \mathrm{~g} \mathrm{~g}^{-1}$ and $0.011 \mathrm{~mA} / \mathrm{cm}^{2}$, 307 respectively. To measure the electrochemically active surface 308 area (ECSA) and roughness factor, electrical double layer 309 capacitance $(\mathrm{Cdl})$ of the $\mathrm{C} 4-\mathrm{SHz} \mathrm{COF}$ was evaluated by 310 measuring the $\mathrm{CV}$ in the non-faradic region at scan rates of $31110-100 \mathrm{mV} / \mathrm{s}$ in $1 \mathrm{M} \mathrm{KOH}$ at a potential ranging from 0 to $3120.1 \mathrm{~V}(\mathrm{Ag} / \mathrm{AgCl})$ and is shown in Figure S15a, Supporting 313 Information. The value of $\mathrm{Cdl}$ is estimated from the linear 314 slope and found to be $2.75 \mathrm{mF} \mathrm{cm}^{-2}$ (Figure S15b, Supporting 315 Information). The ECSA and $R_{\mathrm{f}}$ values of the $\mathrm{C} 4-\mathrm{SHz} \mathrm{COF}$ 316 were estimated to be $68.75 \mathrm{~cm}^{2}$ and 968.30 , respectively. Thus, the $\mathrm{C} 4-\mathrm{SHz}$ COF shows a high electrochemical catalytic 317 surface area that may be due to the exposed excess nitrogen 318 atom on the surface, which plays as the active sites for the OER 319 activity. The high surface area and the porous structure can 320 facilitate the diffusion of the electrolyte to access more number 321 of reactant species on the electrode surface that resulted in an 322 enhanced performance during the OER. The high mass and 323 specific activity of the $\mathrm{C} 4-\mathrm{SHz}$ COF may also be associated 324 with fast charge transfer during the OER process. The 325 electrochemical impedance spectroscopic (EIS) Nyquist plot 326 of the C4-SHz COF is also presented in Figure 5e. The smaller 327 polarization resistance of the $\mathrm{C} 4-\mathrm{SHz} \mathrm{COF}$ indicates the higher 328 charge transfer kinetics and faster electron transfer process that 329 supports the OER activity. ${ }^{46}$ The durability is another key 330 factor to evaluate the catalytic activity in practical application. 331 The long-term durability of the C4-SHz COF has been studied 332 by chronopotentiometry measurements. The time-dependent 333 chronopotentiometry measurements demonstrate that the C4- 334 $\mathrm{SHz} \mathrm{COF}$ is a stable material and can work efficiently for more 335 than $11 \mathrm{~h}$ at a current density of $10 \mathrm{~mA} / \mathrm{cm}^{2}$ (Figure $5 \mathrm{f}$ ). 336 Further, the stability of the $\mathrm{C} 4-\mathrm{SHz} \mathrm{COF}$ at higher current 337 densities (20 and $50 \mathrm{~mA} / \mathrm{cm}^{2}$ ) has been checked with time- 338 dependent chronopotentiometry measurement (Figure S16, 339 Supporting Information). The as-synthesized material shows a 340 quite stable response at higher current densities as well. The 341 above measurements demonstrate the enhanced efficiency and 342 robustness of the $\mathrm{C} 4-\mathrm{SHz} \mathrm{COF}$ toward the OER and validate 343 its promising application in future energy devices. It is quite 344 essential to understand the structure, morphology, and any 345 alternation of the bonding connectivity of the C4-SHz COF 346 after the durability test. The post-OER analysis validates the 347 robust properties of the electrocatalyst for practical application. 348 Therefore, PXRD and FTIR analyses have been carried out 349 after the stability test. In the PXRD patterns, no change in the 350 crystal phase was observed (Figure S17, Supporting 351 Information). This result suggested the stability of the 352 crystalline COF structure in the electrocatalyst. FTIR spectra 353 confirm the retention of the bonding connectivity within the 354 organic framework (Figure S18, Supporting Information) after 355 the OER stability test, suggesting the $\mathrm{C} 4-\mathrm{SHz} \mathrm{COF}$ as a robust 356 material.

The mechanism of the OER process and the efficiency of the 358 $\mathrm{C} 4-\mathrm{SHz} \mathrm{COF}$ material toward the electrochemical OER are 359 rationalized through a density functional theory study based on 360 first-principle calculations using the VASP simulation package. 361 We have constructed a periodic monolayer model of $\mathrm{C} 4-\mathrm{SHz}$ o 362 (cell size: $31.09 \times 27.22 \AA^{2}$ ) consisting of 123 atoms, as shown 363 in Figure 6a. The efficiency of the OER can be determined by $364 \mathrm{f} 6$ calculating the reaction free energies of the individual 365 elementary steps. ${ }^{47}$ Therefore, the free-energy change for the 366 adsorption of the intermediates (i.e., $\mathrm{OH}^{*}, \mathrm{O}^{*}$, and $\mathrm{OOH}^{*}$ ) 367 on the $\mathrm{C} 4-\mathrm{SHz}$ surface has been calculated, and free-energy 368 profiles for OER pathways at $U=0$ and $1.23 \mathrm{~V}$ are given in 369 Figure 6c. For $\mathrm{OH}^{-}$adsorption on the $\mathrm{C} 4-\mathrm{SHz}$ surface, there 370 are seven possible sites, including the $S$ atom (Figure $6 \mathrm{~b}$ and 371 Figure S19, Supporting Information). However, adsorption of 372 $\mathrm{OH}^{-}$is more favorable on the $\mathrm{C} 2$ site with the highest $\mathrm{OH}^{-} 373$ adsorption energy of $-1.61 \mathrm{eV}$ (Figure $6 \mathrm{~b}$ and Table S4). 374 However, there are very weak interactions between $\mathrm{OH}^{-}$and 375 either the N3 or S site (Figure S19e,f). Therefore, the active 376 site for $\mathrm{OH}^{-}$adsorption is predominantly the $\mathrm{C} 2$ site. From 377 the free-energy profile diagram (Figure 6c), it is evident that 378 $\mathrm{OOH}^{*}$ adsorption with the highest (most positive) free-energy 379 


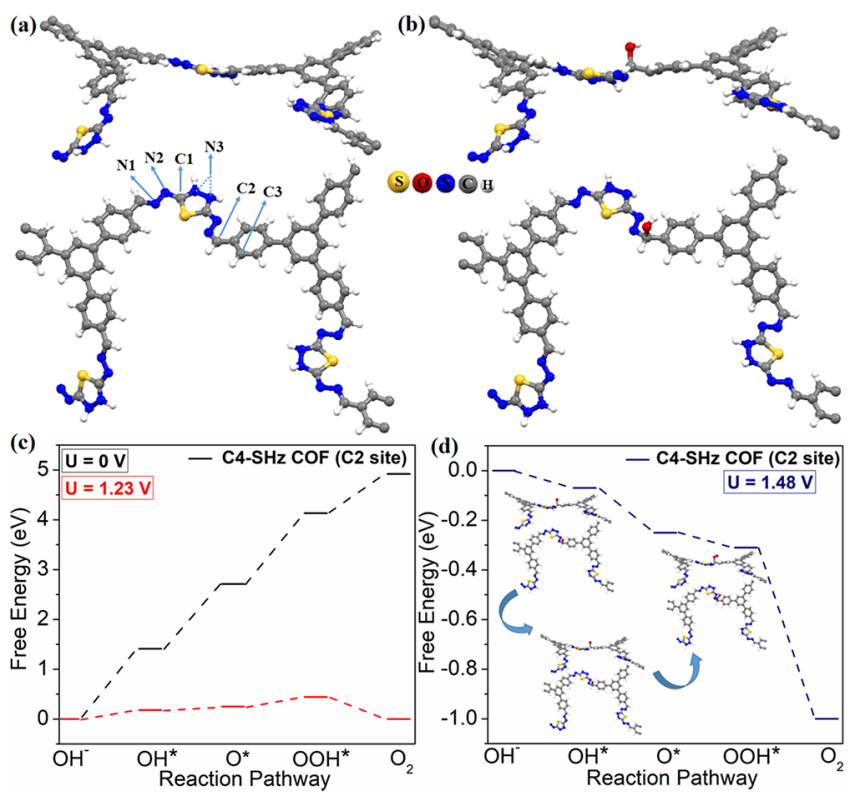

Figure 6. (a) Theoretically optimized structure of the $\mathrm{C} 4-\mathrm{SHz}$ monolayer (different $\mathrm{C}$ and $\mathrm{N}$ sites are marked) and (b) most stable structure of the $\mathrm{OH}^{*}$ adsorbed $\mathrm{C} 4-\mathrm{SHz}$ surface (all other possible $\mathrm{OH}^{-}$adsorption sites are shown in Figure S19, Supporting Information). (c) Free-energy profile for the OER pathway in alkaline medium on the $\mathrm{C} 2$ site at $U=0$ and $1.23 \mathrm{~V}$ for the $\mathrm{C} 4-\mathrm{SHz} \mathrm{COF}$. (d) Free-energy profile at the experimentally determined onset potential, i.e., at an applied bias of $U=1.48 \mathrm{~V}$ (inset shows the structures of adsorption intermediates $\mathrm{OH}^{*}, \mathrm{O}^{*}$, and $\mathrm{OOH}^{*}$ on the $\mathrm{C} 2$ site of the $\mathrm{C} 4-\mathrm{SHz}$ surface).

380 value is the rate-determining step during the OER process for 381 the $\mathrm{C} 4-\mathrm{SHz} \mathrm{COF}^{47}$

382 The free-energy values of $\mathrm{OOH}^{*}$ adsorption on the $\mathrm{C} 4-\mathrm{SHz}$ 383 surface are 4.13 and $0.44 \mathrm{eV}$ at $U=0$ and $1.23 \mathrm{~V}$. This finding 384 is consistent with the earlier reported COF material as the 385 metal-free OER electrocatalyst. ${ }^{33}$ To get further insight about 386 the excellent electrocatalytic activity of the $\mathrm{C} 4-\mathrm{SHz} \mathrm{COF}$, we 387 have performed density of states (DOS) analysis. Total and 388 projected density of states (TDOS and PDOS) analysis clearly 389 demonstrates that the VBM is mainly composed of the $2 p$ 390 orbital of $\mathrm{C}$ atoms, whereas the $2 \mathrm{p}$ orbitals of heteroatoms, i.e., $391 \mathrm{~N}$ and $\mathrm{S}$ atoms, contribute to the CBM (Figure S20, 392 Supporting Information). Among various C sites, as evident 393 from Figure S20b, the major contribution to the VBM comes 394 from the C2 sites. Therefore, upon adsorption of energy, holes 395 will be generated mainly on $\mathrm{C}$ atoms (especially on the C2 396 atom), and heteroatom sites will be electron-rich. For the OER 397 process in alkaline medium, $\mathrm{OH}^{-}$is oxidized to $\mathrm{O}_{2}$ after 398 absorbing holes from the active $\mathrm{C} 2$ sites, which is consistent 399 with previously reported COFs and heteroatom-doped 400 graphene systems. ${ }^{33,48,49}$ Besides, we have determined the 401 free-energy profile for the OER pathway at an applied bias of $4021.48 \mathrm{~V}$ (Figure 6d), which is the experimentally determined 403 onset potential. Interestingly, the energy profile diagram 404 exhibits the downhill OER pathway at $U=1.48 \mathrm{~V}$, validating 405 the experimental findings of the OER onset overpotential. 406 Moreover, the downhill OER pathway at $U=1.48 \mathrm{~V}$ also 407 indicates that the lower overpotential (merely $250 \mathrm{mV}$ ) arises 408 due to the $\mathrm{C} 2$ active site on the surface. ${ }^{33}$

\section{CONCLUSIONS}

409

In summary, we have fabricated a novel thiadiazole-based 410 covalent organic framework, $\mathrm{C} 4-\mathrm{SHz} \mathrm{COF}$, through the Schiff 411 base condensation polymerization reaction between 1,3,5- 412 tris(4-formylphenyl)benzene and 2,5-dihydrazinyl-1,3,4-thia- 413 diazole under vacuum in a sealed tube. The resultant material 414 displayed a unique molecular architecture, high porosity, BET 415 surface area, and accessible active sites, which could enable this 416 $\mathrm{COF}$ as a superior self-supported metal-free OER electro- 417 catalyst. In the alkaline system, the material showed a low 418 onset potential of $270 \mathrm{mV}$, and the material achieved a current 419 density of $10 \mathrm{~mA} / \mathrm{cm}^{2}$ with a lower overpotential of $320 \mathrm{mV} .420$ The accomplished OER activity is comparable to other best 421 reported metal-free catalysts with excellent durability. There- 422 fore, the catalytic performance exhibited by $\mathrm{C} 4-\mathrm{SHz} \mathrm{COF} 423$ suggests that it may replace metal-free carbon-based nanoma- 424 terials and could be a promising electrocatalyst for future 425 energy conversion from abundant water resources.

426

\section{ASSOCIATED CONTENT}

\section{SI Supporting Information}

428

The Supporting Information is available free of charge at 429 https://pubs.acs.org/doi/10.1021/acscatal.9b05470.

430

Materials, methods and characterization tools, exper- 431 imental details, Pawley refined powder X-ray profile with 432 other related data, simulated $\mathrm{N}_{2}$ adsorption isotherm, 433 TGA profile, comparison table with other reported 434 catalysts, CV plot of materials before LSV measurement, 435 $i R$-corrected LSV curve, exchange current density plot, 436 RRDE measurement plot, ECSA plot, stability at 437 different density plot, PXRD and FTIR of used COF 438 materials, and computational OER mechanism related 439 data (PDF)

\section{AUTHOR INFORMATION}

\section{Corresponding Authors}

Bikash Kumar Jena - Material Chemistry Department, CSIR- 444 Institute of Minerals and Materials Technology, Bhubaneswar 445 751013, India; Academy of Scientific \& Innovative Research 446 (AcSIR), Ghaziabad 201002, India; 이이.orcid.o000-0003- 447 1794-4430; Email: msab@iacs.res.in

Asim Bhaumik - School of Materials Sciences, Indian Association for the Cultivation of Science, Jadaupur 7 ( Association for the Cultivation of Science, Jadavpur 700032, 450 India; @ orcid.org/0000-0002-4907-7418; Email: bikash@451 immt.res.in

$$
452
$$

\section{Authors}

Sujan Mondal - School of Materials Sciences, Indian Association 454 for the Cultivation of Science, Jadavpur 700032, India 455

Bishnupad Mohanty - Material Chemistry Department, CSIR- 456 Institute of Minerals and Materials Technology, Bhubaneswar 457 751013, India; (i) orcid.org/0000-0001-7320-1223 458

Maryam Nurhuda - School of Science and Technology, $\quad 459$ Nottingham Trent University, NG11 8NS Nottingham, U.K. 460

Sasanka Dalapati - Institute of Chemical Technology-Indian Oil 461 Odisha Campus (ICT-IOC), Bhubaneswar, Odisha 751013, 462 India

Rajkumar Jana - School of Physical Sciences, Indian Association 464 for the Cultivation of Science, Jadavpur 700032, India 465 
466 Matthew Addicoat - School of Science and Technology,

$467 \quad$ Nottingham Trent University, NG11 8NS Nottingham, U.K.;

468 이이. orcid.org/0000-0002-5406-7927

469 Ayan Dutta - School of Physical Sciences, Indian Association for

470 the Cultivation of Science, Jadavpur 700032, India;

471 orcid.org/0000-0001-6723-087X

472 Complete contact information is available at:

473 https://pubs.acs.org/10.1021/acscatal.9b05470

\section{Author Contributions}

475 S.M. and B.M. contributed equally. All authors have given 476 approval to the final version of the manuscript.

477 Notes

478 The authors declare no competing financial interest.

\section{ACKNOWLEDGMENTS}

480 S.M. acknowledges CSIR, New Delhi, India. A.B. acknowl481 edges DST-SERB, New Delhi, for a core research grant. 482 Assistance from CSS, IACS Kolkata is acknowledged. M.A. 483 acknowledges support from EPSRC, EP/S015868/1, and HPC 484 resources on Thomas via the Materials Chemistry Consortium, 485 EP/P020194. B.P.M. is grateful to UGC, New Delhi, for the 486 fellowship, and B.K.J. is grateful to MNRE, New Delhi, BRNS, 487 Mumbai, India, and CSIR, New Delhi, India, for the financial 488 support.

\section{$489 \square$ REFERENCES}

490 (1) Roger, I.; Shipman, M. A.; Symes, M. D. Earth-Abundant 491 Catalysts for Electrochemical and Photoelectrochemical Water 492 Splitting. Nat. Rev. Chem. 2017, 1, 1-13.

493 (2) Zhang, J.; Zhao, Z.; Xia, Z.; Dai, L. A Metal-Free Bifunctional 494 Electrocatalyst for Oxygen Reduction and Oxygen Evolution 495 Reactions. Nat. Nanotechnol. 2015, 10, 444-452.

496 (3) Liu, X.; Dai, L. Carbon-Based Metal-Free Catalysts. Nat. Rev. 497 Mater. 2016, 1, 16064-16076.

498 (4) Mohanty, B.; Jena, B. K.; Basu, S. Single Atom on the 2D Matrix: 499 An Emerging Electrocatalyst for Energy Applications. ACS Omega 500 2020, 5, 1287-1295.

501 (5) Kamila, S.; Mohanty, B.; Samantara, A. K.; Guha, P.; Ghosh, A.; 502 Jena, B.; Satyam, P. V.; Mishra, B. K.; Jena, B. K. Highly Active 2D 503 Layered $\mathrm{MoS}_{2}$-rGO Hybrids for Energy Conversion and Storage 504 Applications. Sci. Rep. 2017, 7, 8378-8313.

505 (6) Bhanja, P.; Mohanty, B.; Patra, A. K.; Ghosh, S.; Jena, B. K.; 506 Bhaumik, A. $\mathrm{IrO}_{2}$ and Pt Doped Mesoporous $\mathrm{SnO}_{2}$ Nanospheres as 507 Efficient Electrocatalysts for the Facile OER and HER. Chem CatChem 508 2019, 11, 583-592.

509 (7) Siracusano, S.; Van Dijk, N.; Payne-Johnson, E.; Baglio, V.; 510 Arico, A. S. Nanosized $\mathrm{IrO}_{\mathrm{x}}$ and $\mathrm{IrRuO}_{\mathrm{x}}$ Electrocatalysts for the $\mathrm{O}_{2}$ 511 Evolution Reaction in PEM Water Electrolysers. Appl. Catal. B: 512 Environ. 2015, 164, 488-495.

513 (8) Kayal, U.; Mohanty, B.; Bhanja, P.; Chatterjee, S.; Chandra, D.; 514 Hara, M.; Kumar Jena, B.; Bhaumik, A. Ag Nanoparticle-Decorated, 515 Ordered Mesoporous Silica as an Efficient Electrocatalyst for Alkaline 516 Water Oxidation Reaction. Dalton Trans. 2019, 48, 2220-2227.

517 (9) Mohanty, B.; Ghorbani-Asl, M.; Kretschmer, S.; Ghosh, A.; 518 Guha, P.; Panda, S. K.; Jena, B.; Krasheninnikov, A. V.; Jena, B. K. $519 \mathrm{MoS}_{2}$ Quantum Dots as Efficient Catalyst Materials for the Oxygen 520 Evolution Reaction. ACS Catal. 2018, 8, 1683-1689.

521 (10) Guo, H.-P.; Ruan, B.-Y.; Luo, W.-B.; Deng, J.; Wang, J.-Z.; Liu, 522 H.-K.; Dou, S.-X. Ultrathin and Edge-Enriched Holey Nitride 523 Nanosheets as Bifunctional Electrocatalysts for the Oxygen and 524 Hydrogen Evolution Reactions. ACS Catal. 2018, 8, 9686-9696.

525 (11) Dutta, A.; Samantara, A. K.; Dutta, S. K.; Jena, B. K.; Pradhan, 526 N. Surface-Oxidized Dico-balt Phosphide Nanoneedles as a Nonpre527 cious, Durable, and Efficient OER Catalyst. ACS Energy Lett. 2016, 1, 528 169-174.
(12) Dalai, N.; Mohanty, B.; Mitra, A.; Jena, B. Highly Active 529 Ternary Nickel-Iron Oxide as Bifunctional Catalyst for Electro- 530 chemical Water Splitting. ChemistrySelect 2019, 4, 7791-7796. 531 (13) Wu, H.; Yang, T.; Du, Y.; Shen, L.; Ho, G. W. Identification of 532 Facet-Governing Reactivity in Hematite for Oxygen Evolution. Adv. 533 Mater. 2018, 30, 1804341-1804349.

534

(14) Hu, Q.; Li, G.; Liu, X.; Zhu, B.; Chai, X.; Zhang, Q.; Liu, J.; He, 535 C. Superhydrophilic Phytic-Acid-Doped Conductive Hydrogels as 536 Metal-Free and Binder-Free Electrocatalysts for Efficient Water 537 Oxidation. Angew. Chem., Int. Ed. 2019, 58, 4318-4322. 538

(15) Lai, J.; Li, S.; Wu, F.; Saqib, M.; Luque, R.; Xu, G. 539 Unprecedented Metal-Free 3D Porous Carbonaceous Electrodes for 540 Full Water Splitting. Energy Environ. Sci. 2016, 9, 1210-1214. 541

(16) Zhao, Y.; Yang, N.; Yao, H.; Liu, D.; Song, L.; Zhu, J.; Li, S.; 542 Gu, L.; Lin, K.; Wang, D. Stereodefined Codoping of Sp-N and S 543 Atoms in Few-Layer Graphdiyne for Oxygen Evolution Reaction. J. 544 Am. Chem. Soc. 2019, 141, 7240-7244.

(17) Li, Q.; Yang, C.; Wu, L.; Wang, H.; Cui, X. Converting 546 Benzene into $\gamma$-Graphyne and Its Enhanced Electrochemical Oxygen 547 Evolution Performance. J. Mater. Chem. A 2019, 7, 5981-5990. 548

(18) Côté, A. P.; Benin, A. I.; Ockwig, N. W.; O’Keeffe, M.; Matzger, 549 A. J.; Yaghi, O. M. Porous, crystalline, covalent organic frameworks. 550 Science 2005, 310, 1166-1170.

(19) Song, Y.; Sun, Q.; Aguila, B.; Ma, S. Opportunities of Covalent 552 Organic Frameworks for Advanced Applications. Adv. Sci. 2019, 6, 553 1801410.

(20) Ding, S. Y.; Wang, W. Covalent organic frameworks (COFs): 555 from design to applications. Chem. Soc. Rev. 2013, 42, 548-568. 556

(21) Zhou, J.; Wang, B. Emerging Crystalline Porous Materials as a 557 Multifunctional Platform for Electrochemical Energy Storage. Chem. 558 Soc. Rev. 2017, 46, 6927-6945.

(22) Gomes, R.; Bhaumik, A. A New Triazine Functionalized 560 Luminescent Covalent Organic Framework for Nitroaromatic Sensing 561 and $\mathrm{CO}_{2}$ Storage. RSC $A d v$ 2016, 6, 28047-28054. 562

(23) Briega-Martos, V.; Ferre-Vilaplana, A.; de la Peña, A.; Segura, J. 563 L.; Zamora, F.; Feliu, J. M.; Herrero, E. An Aza-Fused $\pi$-Conjugated 564 Microporous Framework Catalyzes the Production of Hydrogen 565 Peroxide. ACS Catal. 2017, 7, 1015-1024.

(24) Jin, E.; Asada, M.; Xu, Q.; Dalapati, S.; Addicoat, M. A.; Brady, 567 M. A.; Xu, H.; Nakamura, T.; Heine, T.; Chen, Q.; Jiang, D. Two- 568 dimensional $\mathrm{sp}^{2}$ carbon-conjugated covalent organic frameworks. 569 Science 2017, 357, 673-676.

(25) Wang, H.; Zeng, Z.; Xu, P.; Li, L.; Zeng, G.; Xiao, R.; Tang, Z.; 571 Huang, D.; Tang, L.; Lai, C.; et al. Recent Progress in Covalent 572 Organic Framework Thin Films: Fabrications, Applications and 573 Perspectives. Chem. Soc. Rev. 2019, 48, 488-516.

(26) Valentino, L.; Matsumoto, M.; Dichtel, W. R.; Mariñas, B. J. 575 Environ. Sci. Technol. 2017, 51, 14352-14359. 576

(27) Lohse, M. S.; Bein, T. Covalent Organic Frameworks: 577 Structures, Synthesis, and Applications. Adv. Funct. Mater. 2018, 28, 578 1705553.

(28) Mullangi, D.; Dhavale, V.; Shalini, S.; Nandi, S.; Collins, S.; 580 Woo, T.; Kurungot, S.; Vaidhyanathan, R. Low-Overpotential 581 Electrocatalytic Water Splitting with Noble-Metal-Free Nanoparticles 582 Supported in a $\mathrm{sp}^{3} \mathrm{~N}$-Rich Flexible COF. Adv. Energy Mater. 2016, 6, 583 1600110. 584

(29) Kamiya, K.; Kamai, R.; Hashimoto, K.; Nakanishi, S. Platinum- 585 Modified Covalent Triazine Frameworks Hybridized with Carbon 586 Nanoparticles as Methanol-Tolerant Oxygen Reduc-tion Electro- 587 catalysts. Nat. Commun. 2014, 5, 5040.

(30) Aiyappa, H. B.; Thote, J.; Shinde, D. B.; Banerjee, R.; Kurungot, 589 S. Cobalt-Modified Covalent Organic Framework as a Robust Water 590 Oxidation Electrocatalyst. Chem. Mater. 2016, 28, 4375-4379. 591

(31) Wu, D.; Xu, Q.; Qian, J.; Li, X.; Sun, Y. Bimetallic Covalent 592 Organic Frameworks for Constructing Multifunctional Electrocatalyst. 593 Chem. - Eur. J. 2019, 25, 3105-3111.

(32) Sick, T.; Hufnagel, A. G.; Kampmann, J.; Kondofersky, I.; Calik, 595 M.; Rotter, J. M.; Evans, A.; Döblinger, M.; Herbert, S.; Peters, K.; 596 Böhm, D.; Knochel, P.; Medina, D. D.; Fattakhova-Rohlfing, D.; Bein, 597 
598 T. Oriented Films of Conjugated 2D Covalent Organic Frameworks 599 as Photocathodes for Water Splitting. J. Am. Chem. Soc. 2017, 140, $6002085-2092$.

601 (33) Yang, C.; Yang, Z.-D.; Dong, H.; Sun, N.; Lu, Y.; Zhang, F.-M.; 602 Zhang, G. Theory-Driven Design and Targeting Synthesis of a 603 Highly-Conjugated Basal-Plane 2D Covalent Organic Framework for 604 Metal-Free Electrocatalytic OER. ACS Energy Lett. 2019, 4, 22516052258

606 (34) Sick, T.; Rotter, J. M.; Reuter, S.; Kandambeth, S.; Bach, N. N.; 607 Döblinger, M.; Merz, J.; Clark, T.; Marder, T. B.; Bein, T.; Medina, D. 608 D. Switching on and off Interlayer Correlations and Porosity in 2D 609 Covalent Organic Frameworks. J. Am. Chem. Soc. 2019, 141, 1257061012581.

611 (35) Mondal, S.; Kundu, S. K.; Bhaumik, A. A Facile Approach for 612 the Synthesis of Hydroxyl-Rich Microporous Organic Networks for 613 Efficient $\mathrm{CO}_{2}$ Capture and $\mathrm{H}_{2}$ Storage. Chem. Commun. 2017, 53, $6142752-2755$.

615 (36) Bandyopadhyay, S.; Anil, A. G.; James, A.; Patra, A. 616 Multifunctional Porous Organic Polymers: Tuning of Porosity, $617 \mathrm{CO}_{2}$, and $\mathrm{H}_{2}$ Storage and Visible-Light-Driven Photocatalysis. ACS 618 Appl. Mater. Interfaces 2016, 8, 27669-27678.

619 (37) Ji, G.; Yang, Z.; Zhang, H.; Zhao, Y.; Yu, B.; Ma, Z.; Liu, Z. 620 Hierarchically Mesoporous O-Hydroxyazobenzene Polymers: Syn621 thesis and Their Applications in $\mathrm{CO}_{2}$ Capture and Conversion. 622 Angew. Chem., Int. Ed. 2016, 55, 9685-9689.

623 (38) Liu, F.; Huang, K.; Yoo, C.-J.; Okonkwo, C.; Tao, D.-J.; Jones, 624 C. W.; Dai, S. Facilely Synthesized Meso-Macroporous Polymer as 625 Support of Poly (Ethyleneimine) for Highly Efficient and Selective 626 Capture of $\mathrm{CO}_{2}$. Chem. Eng. J. 2017, 314, 466-476.

627 (39) Dalapati, S.; Addicoat, M.; Jin, S.; Sakurai, T.; Gao, J.; Xu, H.; 628 Irle, S.; Seki, S.; Jiang, D. Rational Design of Crystalline Super629 microporous Covalent Organic Frameworks with Triangular Top630 ologies. Nat. Commun. 2015, 6, 7786.

631 (40) Merí-Bofí, L.; Royuela, S.; Zamora, F.; Ruiz-González, M. L.; 632 Segura, J. L.; Muñoz-Olivas, R.; Mancheño, M. J. Thiol grafted imine633 based covalent organic frameworks for water re-mediation through 634 selective removal of $\mathrm{Hg}(\mathrm{II})$. J. Mater. Chem. A 2017, 5, 17973-17981. 635 (41) Gao, Q.; Li, X.; Ning, G.-H.; Leng, K.; Tian, B.; Liu, C.; Tang, 636 W.; Xu, H.-S.; Loh, K. P. Highly photoluminescent two-dimensional 637 imine-based covalent organic frameworks for chemical sensing. Chem. 638 Commun. 2018, 54, 2349-2352.

639 (42) Waller, P. J.; Gándara, F.; Yaghi, O. M. Chemistry of Covalent 640 Organic Frameworks. Acc. Chem. Res. 2015, 48, 3053-3063.

641 (43) Mondal, S.; Chatterjee, S.; Mondal, S.; Bhaumik, A. Thioether642 Functionalized Covalent Triazine Nanospheres: A Robust Adsorbent 643 for Mercury Removal. ACS Sustainable Chem. Eng. 2019, 7, 73536447361

645 (44) Mohanty, B.; Wei, Y.; Ghorbani-Asl, M.; Krasheninnikov, A. V.; 646 Rajput, P.; Jena, B. K. Revealing the Defect-dominated Oxygen 647 Evolution Activity of Hematene. J. Mater. Chem. A 2020, 8, 6709.

648 (45) Zhao, S.; Wang, Y.; Dong, J.; He, C.-T.; Yin, H.; An, P.; Zhao, 649 K.; Zhang, X.; Gao, C.; Zhang, L.; Lv, J.; Wang, J.; Zhang, J.; Khattak, 650 A. M.; Khan, N. A.; Wei, Z.; Zhang, J.; Liu, S.; Zhao, H.; Tang, Z. 651 Ultrathin Metal-organic Framework nanosheets for Electrocatalytic 652 Oxygen Evolution. Nat. Energy 2016, 1, 16184.

653 (46) Wu, X.; Yang, Y.; Zhang, T.; Wang, B.; Xu, H.; Yan, X.; Tang, 654 Y. ACS Appl. Mater. Interfaces 2019, 11, 39841-39847.

655 (47) Bothra, P.; Pati, S. K. Activity of Water Oxidation on Pure and $656(\mathrm{Fe}, \mathrm{Ni}$, and $\mathrm{Cu})$-Substituted $\mathrm{Co}_{3} \mathrm{O}_{4}$. ACS Energy Lett. 2016, 1, 858657862.

658 (48) Wang, Q.; Ji, Y.; Lei, Y.; Wang, Y.; Wang, Y.; Li, Y.; Wang, S. 659 Pyridinic-N-Dominated Doped Defective Graphene as a Superior 660 Oxygen Electrocatalyst for Ultrahigh-Energy-Density Zn-Air Batteries. 661 ACS Energy Lett. 2018, 3, 1183-1191.

662 (49) Yang, H. B.; Miao, J.; Hung, S.-F.; Chen, J.; Tao, H. B.; Wang, 663 X.; Zhang, L.; Chen, R.; Gao, J.; Chen, H. M.; Dai, L.; Liu, B. 664 Identification of Catalytic Sites for Oxygen Reduction and Oxygen 665 Evolution in N-doped Graphene Materials: Development of Highly
Efficient Metal-free Bifunctional Electrocatalyst. Sci. Adv. 2016, 2, 666 e1501122-e1501132. 